\title{
Chitinase 3-Like-1 Expression in Colonic Epithelial Cells as a Potentially Novel Marker for Colitis-Associated Neoplasia
}

\author{
Chun-Chuan Chen, ${ }^{*}$ Joel Pekow, ${ }^{\dagger}$ Victoria Llado, ${ }^{*}$ \\ Manasa Kanneganti, ${ }^{*}$ Cindy W. Lau, ${ }^{\ddagger}$ \\ Atsushi Mizoguchi, ${ }^{\neq \S}$ Mari Mino-Kenudson, ${ }^{\ddagger}$ \\ Marc Bissonnette ${ }^{\dagger}$ and Emiko Mizoguchi ${ }^{\star \S}$ \\ From the Gastrointestinal Unit, Department of Medicine, the \\ Department of Pathology, ${ }^{\ddagger}$ and the Center for the Study of \\ Inflammatory Bowel Disease, ${ }^{\S}$ Massachusetts General Hospital, \\ Harvard Medical School, Boston, Massachusetts; and the Division \\ of Gastroenterology, Department of Medicine and the Digestive \\ Disease Research Core Center, The University of Chicago, \\ Chicago, Illinois
}

Chitinase 3-like-1 (CHI3L1/YKL-40) is a protein secreted from restricted cell types including colonic epithelial cells (CECs) and macrophages. CHI3L1 is an inflammation-associated molecule, and its expression is enhanced in persons with colitis and colon cancer. The biological function of CHI3L1 on CECs is unclear. In this study, we investigated the role of CHI3L1 on CECs during the development of colitis-associated neoplasia. We analyzed colonic samples obtained from healthy persons and from persons with ulcerative colitis with or without premalignant or malignant changes. DNA microarray and RT-PCR analyses significantly increased CHI3L1 expression in non-dysplastic mucosa from patients with inflammatory bowel disease (IBD) who had dysplasia/adenocarcinoma compared with that in healthy persons and in patients with IBD who did not have dysplasia. As determined by IHC, CHI3L1 was expressed in specific cell types in the crypts of colonic biopsies obtained from patients with ulcerative colitis who have remote dysplasia. Purified CHI3L1 efficiently activated the NF- $\kappa$ B signaling pathway and enhanced the secretion of IL-8 and TNF- $\alpha$ in SW480 human colon cancer cells. In addition, colon cancer cell proliferation and migration were significantly promoted in response to $\mathrm{CHI} 3 \mathrm{L1}$ in these cells. In summary, $\mathrm{CHI} 3 \mathrm{L1}$ may contribute to the proliferation, migration, and neoplastic progression of CECs under inflammatory conditions and could be a useful biomarker for neoplastic changes in patients with IBD. (Am J Pathol 2011, 179:1494-1503; DOI: 10.1016/j.ajpath.2011.05.038)

Chitinase 3-like-1 (CHI3L1, also known as YKL-40 or HCgp39) is classified in the glycosyl hydrolases 18 family based on the structural similarity with other chitinases. ${ }^{1,2}$ However, functionally, CHI3L1 lacks enzymatic activity and belongs to the family of chi-lectins (chitinase-like lectins) that includes $\mathrm{Ym}-1^{3}$ and stabilin-1-interacting chitinase-like protein. ${ }^{4} \mathrm{CHI} 3 \mathrm{~L} 1$ is a $40 \mathrm{kDa}$ protein and is produced by restricted cell types, including colonic epithelial cells (CECs) and macrophages. ${ }^{5-7} \mathrm{CHI}$ L 1 can be detected in the Golgi apparatus and the endoplasmic reticulum, ${ }^{8}$ but its major sites of action seems to be extracellular as a secreted protein. ${ }^{9}$ The secreted form of $\mathrm{CHI}$ L 1 has growth-stimulating effects in connective tissue cells, including synoviocytes and chondrocytes. ${ }^{10}$ In addition, CHI3L1 shows dose-dependent growth-stimulating effects in human fibroblasts and shows similar and synergistic effects with well-characterized mitogen, insulin-like growth factor 1 (IGF-1). ${ }^{11}$ However, the exact biological function of $\mathrm{CHI} 3 \mathrm{~L} 1$ in CECs remains uncertain.

It is well documented that elevated levels of $\mathrm{CHI} 3 \mathrm{~L} 1$ can be detected in the sera of persons with rheumatoid arthritis, bronchial asthma, or inflammatory bowel disease (IBD). ${ }^{12-15}$ Serum CHI3L1 is significantly increased in active but not quiescent IBD. 5,9,15 In agreement with this observation, approximately $64 \%$ of persons with Crohn's disease (CD) who have extra-intestinal manifes-

Supported by grants from the National Institutes of Health (DK80070, DK74454, DK64289, and DK43351 to E.M. and Al81807 to A.M.) and the Eli and Edythe L. Broad Medical Foundation and American Gastroenterological Association Foundation (E.M.). M.K. is the recipient of a 2010 Student Research Fellowship Award from the Crohn's and Colitis Foundation of America Inc.

Accepted for publication May 24, 2011.

Supplemental material for this article can be found at http://ajp. amjpathol.org or at doi: 10.1016/j.ajpath.2011.05.038.

Address reprint requests to Emiko Mizoguchi, M.D., Ph.D., Massachusetts General Hospital, GRJ 702, 55 Fruit St., Boston, MA 02114. E-mail: emizoguchi@partners.org. 
tations such as erythema nodosum and fistulas showed significantly increased serum levels of $\mathrm{CHI} 3 \mathrm{~L} 1 .{ }^{15,16}$ In addition, patients with $\mathrm{CD}$ who had stenotic disease had higher serum $\mathrm{CHI} 3 \mathrm{~L} 1$ than did patients with non-stenotic disease.$^{17}$ Of note, the colonic CHI3L1 mRNA level was increased in persons with active ulcerative colitis (UC) and $C D$ but was in the normal range in persons with quiescent $\mathrm{UC}$ and the uninvolved regions of $\mathrm{CD} .{ }^{5}$ In addition, CHI3L1 serum concentrations seem to be not only highly up-regulated in persons with active $C D$ and UC but also correlated with poor prognosis of solid tumors, including breast cancer and colon cancer. ${ }^{9}$

Patients with chronic IBD have an increased risk of developing colitis-associated cancer, which increases by $0.5 \%$ to $1 \%$ annually after 10 years of chronic inflammation. ${ }^{18} \mathrm{~A}$ growing amount of evidence indicates that various soluble factors produced by epithelial cells and immune cells play a pathogenic role in the carcinogenic change of CECs. ${ }^{1,20} \mathrm{CHI} 3 \mathrm{~L} 1$ seems to be one of the soluble factors that play a pivotal role in protecting cancer cells from undergoing apoptosis, as well as promoting tissue remodeling by interacting with the extracellular matrix and by stimulating angiogenesis. ${ }^{21}$ However, little is know about the role of $\mathrm{CHI}$ L1 in IBD-associated colon cancer.

In this study we show that CHI3L1 expression in CECs is significantly and specifically increased in non-dysplastic mucosa of patients with UC who have dysplasia that is away from the non-dysplastic mucosa (remote dysplasia) as well as colorectal adenocarcinoma; we also show that it may be a reliable biological marker of neoplasia in high-risk individuals. In addition, we demonstrate a new mechanism by which CHI3L1 may contribute to IBDassociated neoplasia through a growth-stimulating effect on enhancing the production of NF- $\kappa \mathrm{B}-$ induced IL-8 and tumor necrosis factor (TNF)- $\alpha$, which presumably are associated with chronic inflammation-mediated malignant transformation in CECs.

\section{Materials and Methods}

\section{Cell Culture}

SW480 and COLO 205 cells were obtained from American Type Culture Collection (Manassas, VA) and were cultured in Dulbecco's modified Eagle's medium with L-glutamine (Cellgro, Lawrence, KS), supplemented with $10 \%(\mathrm{v} / \mathrm{v})$ fetal calf serum (Atlanta Biological Inc., Norcross, GA) and a mixture of antibiotics (penicillin $\mathrm{G}$ and streptomycin) (Cellgro).

\section{Cases}

The total 10, 22, 33, 14, and 10 cases of normal, IBD, IBD with dysplasia/carcinoma, conventional colorectal adenocarcinoma, and colorectal adenoma, respectively, were examined for DNA microarray/RT-PCR analyses and/or immunohistochemical (IHC) analysis.

\section{CHI3L 1 Protein Preparation}

Purified CHI3L1 protein was specially prepared by Quidel Corporation (San Diego, CA) according to the method as previously described. ${ }^{22}$ Briefly, CHI3L1 was collected from culture supernatant of MG-63 cells in serum-free medium. $\mathrm{CHI}$ 3L1 was purified from the supernatants by concentrating glass-fiber-filtered material 20-fold with a $30 \mathrm{kDa}$ screen channel cassette with tangential flow followed by affinity purification by a heparin-sepharose CL-6B column (Amersham Pharmacia Biotech, Piscataway, $\mathrm{NJ})$. The purified $\mathrm{CHI} 3 \mathrm{~L} 1$ protein did not contain endotoxin $(<0.3 \mathrm{ng} / \mathrm{mL})$, as determined by HEK-Blue LPS detection kit (InvivoGen, San Diego, CA).

\section{DNA Microarray Analysis}

Colon biopsies were obtained from the rectosigmoid junction in healthy control subjects as well as patients who had UC with or without dysplasia. RNA was extracted with use of the RNeasy kit (Qiagen, Germantown, $\mathrm{MD}$ ) according to manufacturer's recommendations. In this study, Affymetrix One Cycle reactions were completed using an Affymetrix 1 Cycle HT Kit, following the company's instruction (Affymetrix, Santa Clara, CA). Briefly, after synthesis of CDNA from $1.5 \mu \mathrm{g}$ total RNA, biotin-labeled complementary RNA was prepared by using in vitro transcription reaction. Biotinylated cRNA samples were purified and quantified, and the CRNA reaction products were fragmented. A total of $5 \mu \mathrm{g}$ of fragmented cRNA target was combined with a hybridization cocktail and hybridized to the Affymetrix HT HG-U133 PM plate on an Affymetrix Gene Titan Instrument. The automated hybridization, washing, staining, and scanning of the arrays was completed on the Affymetrix Gene Titan Instrument. The Affymetrix data (CEL files) were imported into the Partek Genomics Suite, and Robust Multichip Average was normalized by the Gene Titan Instrument. Analysis of variance calculation was performed to determine significant differences. The unsupervised hierarchical clustering was performed with Cluster software version 3.0 (http://bonsai. hgc.jp/ mdehoon/software/cluster/software.htm\#ctv), and heat maps were created with JavaTree view software V 1.1.1 (http://jtreeview.sourceforge.net).

\section{mRNA Analysis}

The mRNA levels were assessed using real-time RT-PCR as described previously. ${ }^{5}$ The sequences for the primers used in real-time RT-PCR were obtained from MGH Primer Bank online at http://pga.mgh.harvard.edu/primerbank. We used the following primers for Q-PCR analysis in this study: CHI3L1 F: 5'-TGATGTGACGCTCTACG-3'; GC, R: 5'-AATGGCGGTACTGACTTGATG-3'; $\beta$-actin F: $5^{\prime}$-GCTGTGCTACGTCGCCCTG-3'; and R: 5'-GGAGGAGCTGGAAGCAGCC-3'. Samples obtained from five healthy patients, four patients with $U C$, and seven patients with UC who had dysplasia (listed in Table 1) were analyzed by real-time RT-PCR analysis, based on the availability of RNA samples. 
Table 1. Demographic Characteristics of Healthy Control Subjects, Subjects with UC, and Subjects with UC Who Have Dysplasia

\begin{tabular}{lccc}
\hline \multicolumn{1}{c}{ Characteristic } & $\begin{array}{r}\text { Healthy } \\
\text { control } \\
\text { subjects }\end{array}$ & $\begin{array}{c}\text { Subjects } \\
\text { with UC }\end{array}$ & $\begin{array}{c}\text { Subjects with } \\
\text { UC who have } \\
\text { dysplasia }\end{array}$ \\
\hline No. & 5 & 4 & 13 \\
Age, year, mean & 46 & 48.3 & 46.2 \\
$\begin{array}{l}\text { Sex, male/female } \\
\text { Race, AA/C/A/U }\end{array}$ & $5 / 0$ & $5 / 0$ & $12 / 1$ \\
Year of disease & $2 / 3 / 0 / 0$ & $0 / 3 / 0 / 1$ & $1 / 8 / 1 / 3$ \\
$\quad$ duration, median & NA & 20 & 13.0 \\
$\begin{array}{c}\text { Displasia histology, } \\
\text { LGD/HGD/ }\end{array}$ & $\mathrm{NA}$ & $\mathrm{NA}$ & $4 / 5 / 4$ \\
$\quad \begin{array}{c}\text { adenocarcinoma } \\
\text { Left-sided colitis (\%) }\end{array}$ & $\mathrm{NA}$ & $2(50)$ & $1(8)$ \\
Pancolitis (\%) & $\mathrm{NA}$ & $2(50)$ & $12(92)$ \\
\hline
\end{tabular}

A, Asian; AA, African American; C, Caucasian; HGD, high-grade dysplasia; LGD, low-grade dysplasia; NA, not available; U, unidentified.

\section{Histology and IHC Analysis}

Human surgical samples were fixed in 10\% formalin, and paraffin-embedded tissue sections were stained with H\&E using standard technique. The serial sections were stained with rabbit anti-CHI3L1 (YKL-40) polyclonal antibody (Quidel Corporation) and/or mouse anti-human CD68 monoclonal antibody (Dako, Carpinteria, CA) by the avidinbiotin complex method as previously described. ${ }^{23}$

\section{Human NF-кB Signaling Pathway Microarray Analysis}

Oligo GEArray human NF- $\kappa$ B signaling pathway microarray (SuperArray Bioscience, Frederick, MD) that covers 128 genes related to signal transduction in humans was used. All of the procedures were performed according to the manufacturer's instructions (SuperArray Bioscience). For semiquantification of the results, each spot of array was measured with use of the National Institute of Health Scion image software $\beta 4.03$ for Windows XP (Frederick, MD).

\section{ELISA}

For enzyme-linked immunosorbent assay (ELISA), the procedure was performed following the instruction protocol from R\&D systems (Minneapolis, MN). The optical density at $450 \mathrm{~nm}$ was read by an AutoReader (Bio-Tec Instruments, Burlington, VT). To standardize the assay, recombinant proteins for IL-8 and TNF- $\alpha$ were used as positive controls. A standard curve was created with the optical density from 62.5 to $2000 \mathrm{pg} / \mathrm{mL}$ for recombinant IL-8 and from 31.25 to $1000 \mathrm{pg} / \mathrm{mL}$ for recombinant TNF- $\alpha$. The quantities of soluble IL- 8 and TNF- $\alpha$ in the culture supernatant were calculated using these standard lines. For the NF- $\kappa$ B inhibition experiment, SW480 cells were pretreated with caffeine acid phenethyl ester (Santa Cruz Biotechnology, Santa Cruz, CA) or SP 600125 (BioVision, Mountain View, CA) for 2 hours before stimulating with $\mathrm{CHI} 3 \mathrm{~L} 1$.

\section{Immunoblot Analysis}

Western blot analysis was performed as previously described. Briefly, cells were washed and then homogenized in a lysis buffer containing $50 \mathrm{mmol} / \mathrm{L} / \mathrm{L}$ Tris (pH 8.0), 0.5\% NP-40, 1 mmol/L/L EDTA, 150 mmol/L/L sodium pyrophosphate, $1 \mathrm{mmol} / \mathrm{L} / \mathrm{L}$ sodium orthovanadate, $1 \mathrm{mmo} / \mathrm{L} / \mathrm{L}$ phenylmethylsulfonyl fluoride, and a tablet of protease inhibitor cocktail (Roche Diagnostics, Mannheim, Germany). After being lysed on ice in $100 \mu \mathrm{L}$ lysis buffer for 30 minutes, the cell lysates were centrifuged at $9300 \mathrm{~g}$ for 10 minutes and the supernatant was collected for measuring protein concentration with use of the BCA Protein Assay Kit (Pierce Company, Rockford, IL). I $\mathrm{kB}$ were detected by antibodies obtained from Cell Signaling Technology (Beverly, MA). After stripping antiphospho $I_{\kappa} \mathrm{B}$ antibody using Western blot stripping buffer (Pierce, Rockford, IL), the membranes were reprobed by $\beta$-actin antibodies.

\section{Luciferase Assay}

The pNF $\kappa_{\mathrm{B}}$-Luc reporter plasmid was obtained from Dr. Ramnik J. Xavier (Massachusetts General Hospital, Boston, MA). SW480 cells were seeded at the density of 2 to $3 \times 10^{5}$ cells/well in 24-well tissue culture plates (Corning Incorporated, Corning, NY). After seeding the cells for 24 hours, cells were transfected with $10 \mathrm{ng} /$ well of the reporter plasmids (NF- $\kappa$ B-Luc) and $0.4 \mathrm{ng}$ of Renilla plasmid (control vector) using Lipofectamine 2000 (Invitrogen, Carlsbad, CA). Transfected cells were treated with different concentrations (0 to $80 \mathrm{ng} / \mathrm{mL}$ ) of purifiedCHI3L1 (Quidel) or recombinant-IGF (R\&D Systems). After 24 hours, luciferase activity was measured with use of the Dual-Luciferase Reporter Assay System (Promega, Madison, WI) according to the manufacturer's instructions and normalized relative to Renilla activity.

\section{In Vitro BrdU Incorporation}

CECs were pulse-labeled with $10 \mu \mathrm{mol} / \mathrm{L}$ 5-bromo-2-deoxyuridine (BrdU) (Sigma-Aldrich, St. Louis, MO) in $300 \mu \mathrm{L}$ of culture medium for 1 hour. Cytocentrifuge preparations of BrdU-labeled cells were made with use of a Shandon Southern Cytocentrifuge (Cheshire, England). Each preparation was fixed for 10 minutes in 100\% acetone. Rat antiBrdU monoclonal antibody (SeroTec, Oxford, England) was used to detect BrdU-incorporated cells according to the immunoperoxidase technique described previously. ${ }^{24}$

\section{Boyden-Chamber Assay}

Cell migration assay was measured with use of modified Boyden chambers (8 $\mu \mathrm{m}$ pore, Coster) as described previously. ${ }^{25}$ Briefly, SW480 cells were treated with CHI3L1 protein (Quidel) or PBS for 24 hours before seeding in the upper chamber of the Boyden chamber apparatus; $5 \times 10^{4}$ cells in serum-free media were then added to each upper migration chamber that had been coated with fibronectin (Upstate Biotechnology Inc., Waltham, MA). Medium supplemented with $0.5 \%$ fetal calf serum were added to the lower chamber, and the cells were 
incubated 24 hours. Nonmigratory cells on the upper membrane surface were moved with a sterile cotton swab, and the migratory cells attached to the bottom surface of the membrane were fixed, stained with DAPI, and counted. For inhibitory experiment, SW480 cells were treated with $100 \mu \mathrm{g} / \mathrm{mL}$ of rabbit anti-CHI3L1 polyclonal antibody ${ }^{5}$ or rabbit IgG for 2 hours before treatment with $\mathrm{CHI}$ L1 protein.

\section{Results}

\section{CHI3L1 Expression in UC-Associated Dysplasia}

Patients with active UC had elevated serum levels of CHI3L1 compared with healthy control subjects, a finding in agreement with prior studies of patients with IBD. ${ }^{15,16,17}$ Our group also previously demonstrated that the colonic CHI3L1 mRNA level was increased in areas of active $U C$ and those of CD compared with inactive UC, uninvolved regions of $C D$, and healthy individuals. ${ }^{5}$ In addition, $\mathrm{CHI} 3 \mathrm{~L} 1$ is expressed and secreted by several types of solid tumors, including colon cancer. $9,26,27$ It is well known that CECs become highly proliferative and acquire dysplastic changes in some patients with chronic IBD-so called colitis-associated carcinogenesis. ${ }^{28-30}$ Therefore we hypothesized that $\mathrm{CHI} 3 \mathrm{~L} 1$ might play a pivotal role in dysplastic and/or carcinogenic changes of CECs in patients with UC. To test this hypothesis, we examined CHI3L1 expression in non-dysplastic mucosa of patients who had UC with or without remote dysplasia who showed quiescent disease or mild inflammation. This CHI3L1 expression was examined in a DNA microarray analysis performed at the University of Chicago (Chicago, IL). The demographic characteristics of these populations are summarized in Table 1. Interestingly, CHI3L1 is one of only nine up-regulated genes (more than 10fold) in patients with UC harboring remote dysplasia compared with patients with UC who do not have dysplasia (J. Pekow and M. Bissonnette, manuscript in preparation). CHI3L1 expression was around 20 -fold increased $(P<0.001)$ in patients with UC who harbored remote neoplastic lesions compared with healthy individuals (Figure 1, A and B), while there was a less significant increase $(P=0.079)$ in $\mathrm{CHI}$ L1 expression in patients who had UC but no remote dysplasia compared with healthy individuals. In addition, a significant difference $(P=0.05)$ in $\mathrm{CHI}$ L1 $1 \mathrm{mRNA}$ expression was seen in patients with UC who did and did not harbor remote dysplasia (Figure 1B). We confirmed these DNA microarray data by real-time RT-PCR using colonic biopsy samples obtained from the three groups shown in Table 1 (Figure 1C).

\section{CHIBL1 Is Expressed by Unique Types of Cells in Colonic Crypts from Patients with UC Who Have Early Dysplasia}

To further confirm our DNA microarray analysis and QPCR data at the protein level, we next performed histologic and $\mathrm{CHI} 3 \mathrm{~L} 1 \mathrm{IHC}$ analyses using the samples obtained from patients with quiescent UC with or without
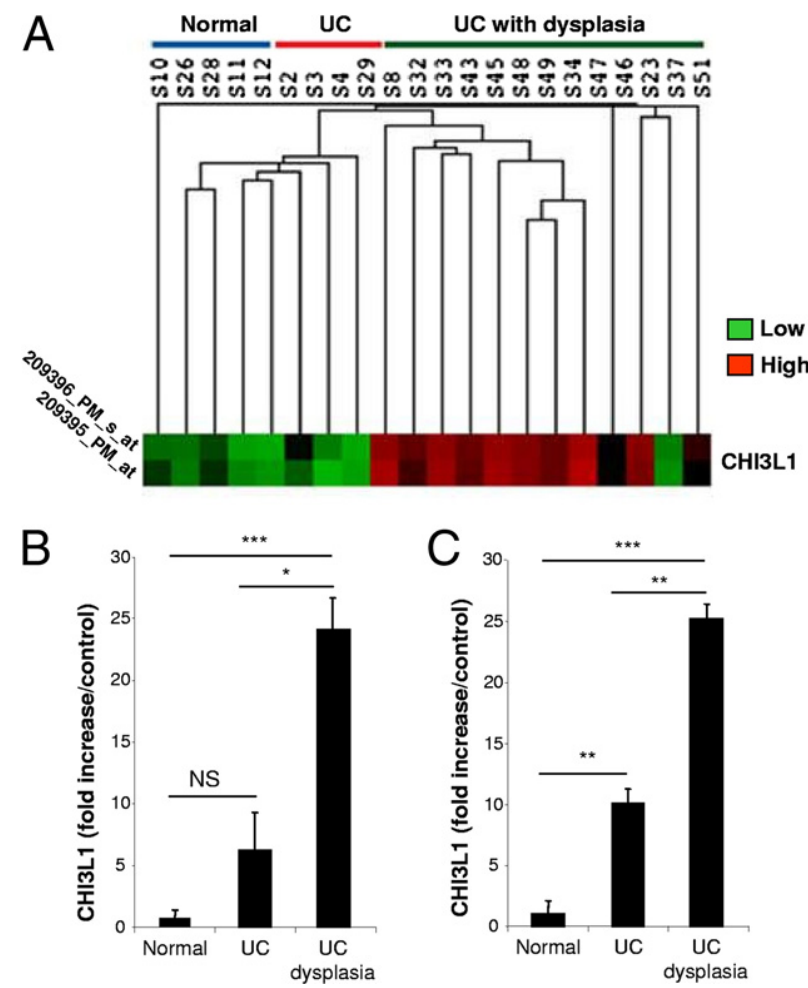

Figure 1. CHI3L1 is up-regulated in CECs of colons obtained from patients with UC who have dysplasia. A and B: DNA microarray data (heat map) of non-dysplastic colonic samples obtained from healthy persons $(n=5)$, patients with UC who did not have dysplasia $(n=4)$, and patients with UC who had remote dysplasia $(n=13)$. These patients with UC showed quiescent disease or mild inflammation in the colon. A: Low and high expression levels were shown as green and red, respectively. Each line of the heat map represents an Affymetrix ID for CHI3L1 (first: 209396_PM_s_at; second: 209395_PM_at). B: Fold increase of CHI3L1 expression in patients with UC who did and did not have dysplasia versus healthy control subjects are shown. C: Real-time RT-PCR analysis of CHI3L1 versus $\beta$-actin mRNA in the colonic biopsy samples used for DNA microarray analysis. ${ }^{*} P=0.05,{ }^{* *} P<$ 0.05 , and ${ }^{* * * *} P<0.01$ (comparison among the indicated groups).

remote dysplasia who were listed in Table 1. As determined by histology, no apparent dysplastic changes occurred in CECs, but mixed cellular infiltration was seen in the lamina propria in both groups of patients with UC (Figure 2, A and B). Many scattered cells in the lamina propria were positively stained with anti-CHI3L1 antibody (Figure 2, C and D) as well as anti-CD68 antibody (macrophage marker) (Figure 2, E and F) in both groups of patients. This finding is compatible with a previous report that $\mathrm{CHI} 3 \mathrm{~L} 1$ is strongly expressed in macrophages in chronic colitis and colorectal cancer cells. ${ }^{5,9}$ In addition, normal colonic mucosa also contains CD68-positive cells, but these are negatively stained with anti-CHI3L1 antibody, as we previously reported. ${ }^{5} \mathrm{CHI} 3 \mathrm{~L} 1$ expression in colonic crypt cells was seen in seven out of the nine patients with UC who had remote dysplasia (Figure 2D), while positive colonocytes were not observed in any of the four patients with UC who did not have dysplasia (Figure 2C). Therefore we next analyzed the CHI3L1 expression in colonic crypt cells in a biopsy sample obtained from patients with UC who had high-grade dysplasia (Figure 3, A and B). As shown in Figure 3, C and D, in dysplastic foci of colon, CHI3L1 was strongly expressed in triangular-shaped cells (presumably stemlike 
UC without dysplasia

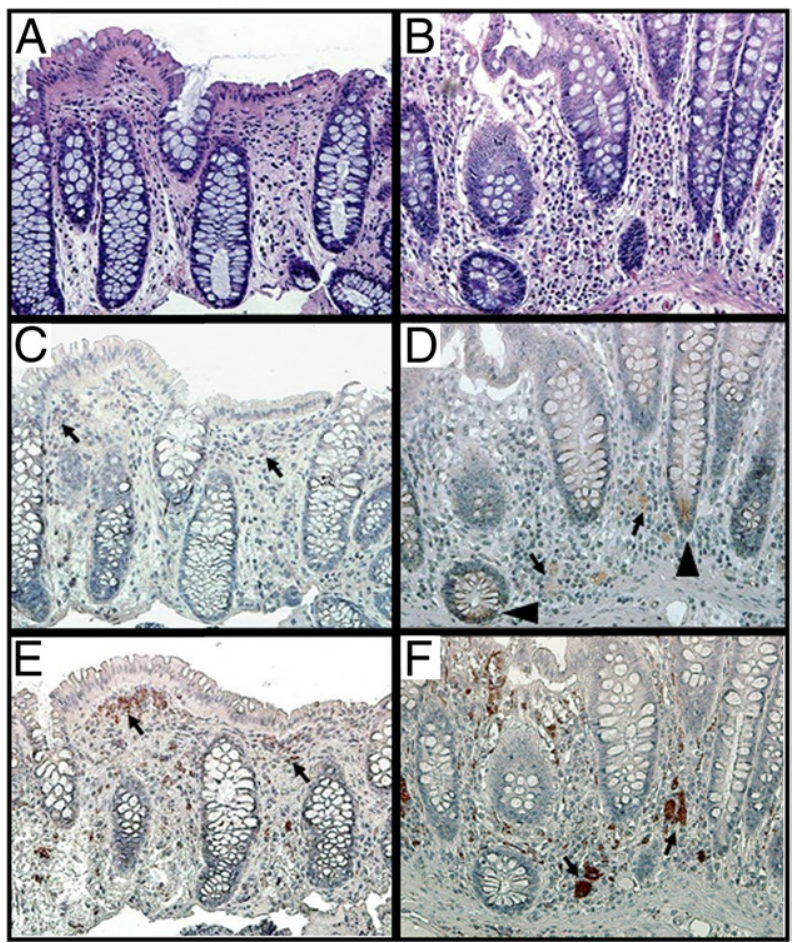

Figure 2. CHI3L1-positive cells are observed in colonic lamina propria and CECs in patients with UC who have remote dysplasia. Serial colonic biopsy specimens obtained from patients with quiescent UC without remote dysplasia $(\mathbf{A}, \mathbf{C}$, and $\mathbf{E})$ or with remote dysplasia $(\mathbf{B}, \mathbf{D}$, and $\mathbf{F})$ were stained with H\&E (A and B), anti-CHI3L1 antibody (C and D) or anti-CD68 antibody $(\mathbf{E}$ and $\mathbf{F})$. Many scattered cells in the lamina propria were positively stained with anti-CHI3L1 and anti-CD68 antibodies (arrows). Some colonocytes at the crypt base were positively stained with anti-CHI3L1 antibody in patients with UC who had remote dysplasia (arrowheads). A-F: objective, $20 \times$.

cells) and Paneth cells, which were filled with granular staining in cytoplasm at the base of crypts. In addition, a few scattered (Figure 3E) or clustered (Figure 3F) neuroendocrine-like cells in the crypts occasionally were stained with anti-CHI3L1 antibody in patients with UC who had dysplasia. In contrast, no CHI3L1-positive colonocytes were identified in patients with UC who did not have dysplasia (Figure 2C) or healthy individuals (data not shown) in this study. The result demonstrated that elevated protein expressions of $\mathrm{CHI} 3 \mathrm{~L} 1$ are observed in distinct cell types of colonic crypts in patients with UC who have dysplasia.

Next, we performed histologic and $\mathrm{CHI} 3 \mathrm{~L} 1 \mathrm{IHC}$ analyses on a surgical resection from a patient with UC who had mucinous adenocarcinoma (see Supplemental Figure S1D at $h$ ttp://ajp.amjpathol.org) and high-grade neuroendocrine carcinoma (Figure 3, G-I) of the colon. Both carcinomas were positively stained with anti-CHI3L1 polyclonal antibody, but CHI3L1 expression was more intense in the neuroendocrine carcinoma (Figure $3, \mathrm{H}$ and I). The patient had deposits in mesenteric lymph nodes from both components (data not shown) and in the liver from the neuroendocrine carcinoma (Figure $3, \mathrm{~J}-\mathrm{L}$ ). The liver metastasis also showed diffuse $\mathrm{CHI}$ L 1 expression (Figure $3 \mathrm{~L}$ ). The results suggest that expression levels of $\mathrm{CHI} 3 \mathrm{~L} 1$ in the primary tumor cells may be positively associated with the invasiveness and metastatic ability of tumor cells. We further examined the CHI3L1 expression in biopsy or surgical specimens that were obtained from randomly selected patients with colonic adenoma $(n=10)$, sporadic colorectal adenocarcinoma $(n=14)$ and IBD-associated adenocarcinoma $(n=7)$ in the Department of Pathology at Massachusetts General Hospital (Table 2). CHI3L1 was specifically stained in Paneth cells, triangular-shaped cells, and/or neuroendocrine-like cells in all cases of IBD-associated cancer and $35.7 \%$ cases of sporadic and advanced colorectal adenocarcinoma, but none of the adenoma cases showed positive staining in these types of cells (see Supplemental Figure S1 at http://ajp.amjpathol.org). Of note, $21.4 \%$ of conventional colorectal cancer cells diffusely and strongly expressed CHI3L1 (see Supplemental Figure S1F at $h$ ttp://ajp.amjpathol.org). In approximately $40 \%$ of adenoma cases, CHI3L1 was expressed in a few areas of focally hyperproliferating CECs (Table 2). Macrophages, neutrophils, dendritic-like cells, and fibroblasts in colonic lamina propria were positively stained with anti-CHI3L1 antibody in $80 \%, 92.8 \%$, and $85.7 \%$ of adenoma, conventional carcinoma, and IBD-associated cancer cases, respectively (Table 2) (see Supplemental Figure S1 at http://ajp.amjpathol.org). These results suggest that CHI3L1 expression in specific types of cells in colonic epithelium, but not in lamina propria cells, is a novel marker for malignant transformation in the colon.

\section{CHI3L1 Specifically Induces IкB Phosphorylation, NF- $\kappa$ B Activation, and TNF- $\alpha /$ IL-8 Production in CECs}

Activation of $\mathrm{NF}-\kappa \mathrm{B}$ signaling is required for many of the biological actions of TNF- $\alpha$ and IL-1 $\beta$. We have previously shown that these two cytokines significantly enhanced the endogenous CHI3L1 expression in SW480 cells. ${ }^{5}$ To determine the genes involved in the NF- $\kappa \mathrm{B}$ pathway activation by $\mathrm{CHI}$ L 1 , we performed DNA array with use of the Oligo GEArray human NF- $\kappa \mathrm{B}$ signaling pathway (SuperArray Biosciences Cooperation, Frederick, MD). After 3 hours of stimulation, purified CHI3L1 protein (Quidel) at a concentration of $80 \mathrm{ng} / \mathrm{mL}$ significantly activated only a restricted number of genes, including IRAK1, IkB $\alpha, N F-k B p 65$ (RelA), and MyD88 in SW480 cells (Figure 4, A and B). These results strongly suggest that $\mathrm{CHI} 3 \mathrm{~L} 1$ specifically stimulates the activation of the NF- $\kappa$ B signaling pathway through MyD88/IRAK1 molecules in the cytoplasm of CECs. NF- $\kappa$ B activation in SW480 cells after stimulation with purified CHI3L1 was marginally increased $(P<0.1)$ and significantly increased $(P<0.01)$ at the concentration of $40 \mathrm{ng} / \mathrm{mL}$ and $80 \mathrm{ng} / \mathrm{mL}$, respectively (Figure 5A). The same concentration of IGF-1 had no significant effect on NF- $\kappa$ B activation in SW480 cells (Figure 5A). Phosphorylation of $I_{\kappa} \mathrm{B} \alpha$ also was dependent on the concentration of $\mathrm{CHI} 3 \mathrm{~L} 1$, and a strong phosphorylation was observed when the cells were stimulated with $80 \mathrm{ng} / \mathrm{mL}$ of CHI3L1 (Figure 5B). Unlike IGF-1 stimulation, CHI3L1 significantly enhanced the pro-inflammatory cytokine TNF- $\alpha$ and prototypic chemokine IL-8 in a dosedependent manner (Figure 5C), and the CHI3L1-mediated 


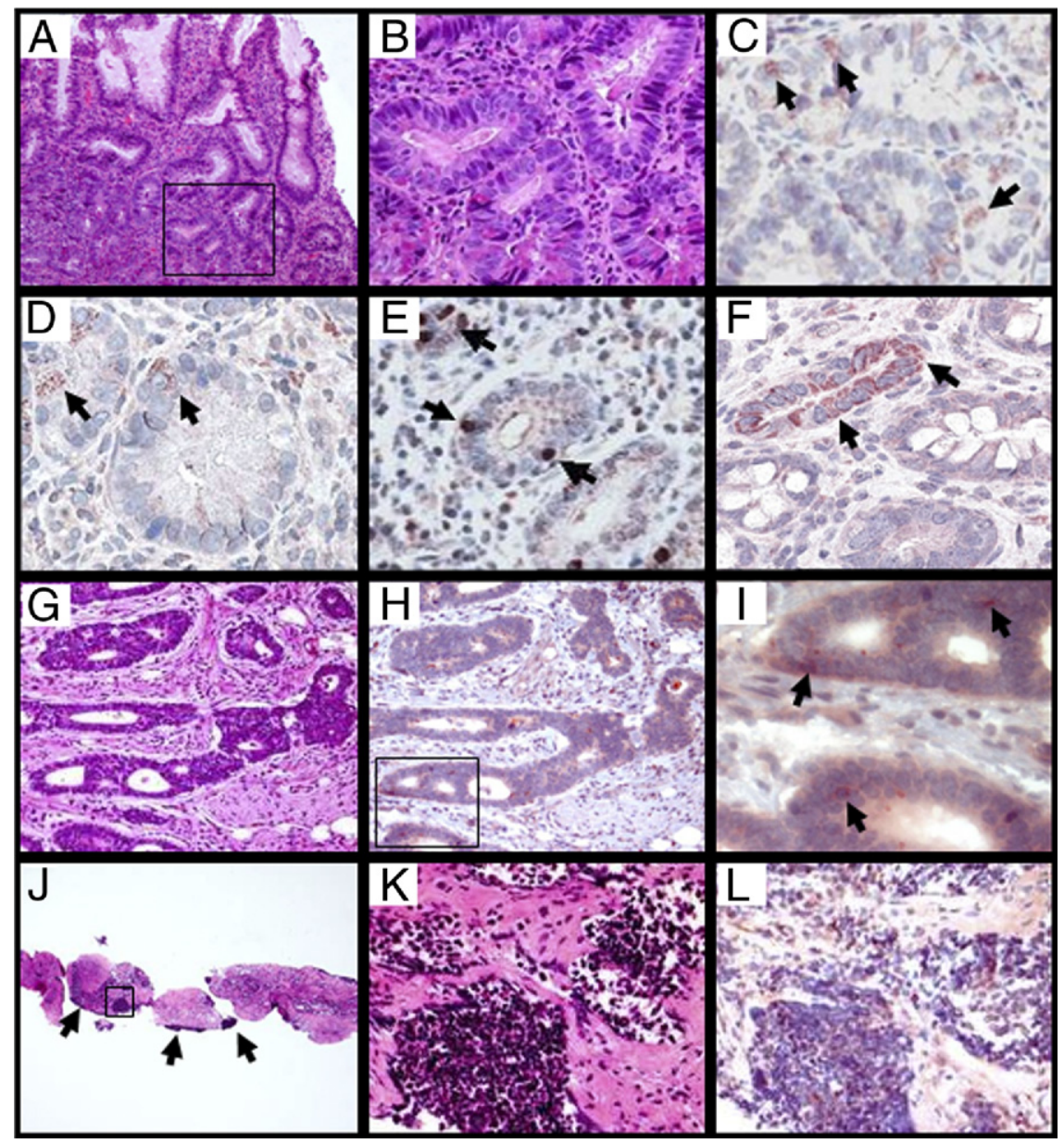

Figure 3. CHI3L1 is expressed by unique type of cells in colons from patients with UC who have dysplasia. A and B: A colonic biopsy specimen obtained from a patient with UC who has high-grade dysplasia is shown (H\&E stain, A: objective, $10 \times$, B: objective, $40 \times$ ). The area indicted by a rectangle in $\mathbf{A}$ corresponds to $\mathbf{B}$. $\mathbf{C}$ and $\mathbf{D}$ : Serial sections of the same case were stained with rabbit anti-CHI3L1 antibody (objective, $40 \times$ ). Arrows show triangular-shaped cells (C) and Paneth cells (D) stained positively with CHI3L1. E and F: Colonic biopsies from patients with UC who had remote dysplasia were stained with anti-CHI3L1 antibody (objective, 40×). Arrows demonstrate scattered (F) and clustered (E) neuroendocrine-like cells in colonic crypts with intense CHI3L-1 expression. G-L: H\&E sections of a colonic resection $(\mathbf{G})$ and a liver biopsy ( $\mathbf{J}$ and $\mathbf{K}$ ) from a patient with UC in whom colonic mucinous adenocarcinoma (not shown) and high-grade neuroendocrine carcinoma (G) developed, followed by liver metastasis ( $\mathbf{J}$ and $\mathbf{K})$. The area indicated by a rectangle in $\mathbf{J}$ corresponds to $\mathbf{K}$. In $\mathbf{J}$, the hepatic parenchyma is completely replaced by neuroendocrine carcinoma (arrows) and desmoplastic stroma (G objective, $10 \times$; J: objective, $4 \times$; and $\mathbf{K}$ : objective, $40 \times)$. $\mathbf{H}, \mathbf{I}$, and $\mathbf{L}$ : The area indicated by a rectangle in $\mathbf{H}$ corresponds to $\mathbf{I}$. Serial sections stained with anti-CHI3L1 antibody show diffuse CHI3L-1 expression in tumor cells (I and $\mathbf{L}$ ). Arrows in I demonstrate presumable neuroendocrine granules with strong CHI3L1 staining (H: objective, 20X; I: objective, 60X; and $\mathbf{L}$ : objective, $40 \times$ ).

enhanced productions of TNF- $\alpha$ and IL-8 were specifically blocked by NF- $\kappa$ B inhibitor (see Supplemental Figure S2 at http://ajp.amjpathol.org).

\section{CHI3L 1 Has Growth-Stimulating Effects on CECs in a Dose-Dependent Manner}

It has been reported previously that purified $\mathrm{CHI}$ L1 shows growth-stimulating effects in human connective tissue cells, including articular chondrocytes and skin fibroblasts. ${ }^{11}$ Because we had demonstrated that both human and mouse colonic crypt cells showed excess elongation and proliferation with increased expression of CHI3L1 during intestinal inflammation, ${ }^{5}$ we hypothesized that $\mathrm{CHI}$ L1 also may have growth-stimulating and cell survival effects on CECs. To test this hypothesis, cell proliferative response was examined by a BrdU-incorporation assay in comparison with IGF-1. Vind et al ${ }^{15}$ previously reported that patients with severe active $U C$ had higher serum $\mathrm{CHI}$ L1 (median, $59 \mu \mathrm{g} / \mathrm{L}$ ) than did patients with inactive UC (33 $\mu \mathrm{g} / \mathrm{L})$, and therefore we chose the range of $\mathrm{CHI} 3 \mathrm{~L} 1$ concentrations from 0 to $80 \mathrm{ng} / \mathrm{mL}$ in this study. After stimulating with a relatively high dose (80 ng/mL) of CHI3L1, an increased number of BrdU-

Table 2. CHI3L1 Expression in Colorectal Adenomas and Adenocarcinomas

\begin{tabular}{|c|c|c|c|c|c|}
\hline & \multicolumn{5}{|c|}{$\mathrm{CHI}$ L1 expression by $I H C$} \\
\hline & \multicolumn{4}{|c|}{ CECS } & \multirow[b]{2}{*}{ LP cells } \\
\hline & Negative & $\begin{array}{l}\text { Scattered } \\
\text { (focal) }(\%)\end{array}$ & Diffuse (\%) & $\begin{array}{c}\text { Specific } \\
\text { cell-types* }(\%)\end{array}$ & \\
\hline Adenoma $(n=10)$ & $6(60)$ & $4(40)$ & $0(0)$ & $0(0)$ & $8(80)$ \\
\hline Conventional and advanced adenocarcinoma $(n=14)$ & $0(0)$ & $11(78.5)$ & $3(21.4)$ & $5(35.7)$ & $13(92.8)$ \\
\hline IBD-associated adenocarcinoma $(n=7)$ & $0(0)$ & $7(100)$ & $0(0)$ & $7(100)$ & $6(85.7)$ \\
\hline
\end{tabular}

Values are number of patients with or without $\mathrm{CHI} 3 \mathrm{~L} 1$ expression

*Specific cell-types include Paneth cells, triangular-shaped cells, and/or neuroendocrine-like cells in CECs.

LP, lamina propria. 

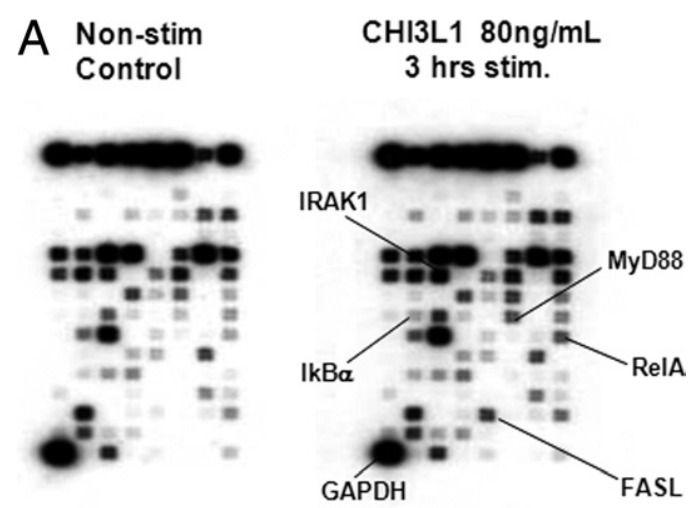

B

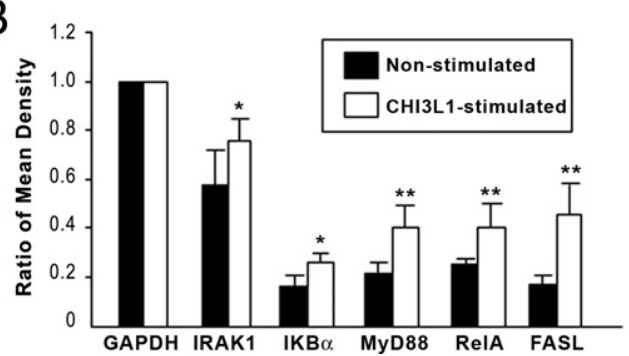

Figure 4. Purified $\mathrm{CHI} 3 \mathrm{~L} 1-e n h a n c e d$ expression of restricted genes. A: A representative result of genes that are associated with signaling pathway in SW480 cells with (right) or without (left) stimulation with purified CHI3L1 $(80 \mathrm{ng} / \mathrm{mL}$ ) for 3 hours. Oligo GEArray human NF- $\kappa \mathrm{B}$ signaling pathway microarray (OHS-025) was used for the analysis following the manufacturer's instruction. Only selected genes (Fas ligand, I $\kappa \mathrm{B} \alpha$, IRAK1, MyD88, and RelA) were up-regulated after 3 hours stimulation with CHI3L1. B: Semiquantitative data of the microarray [normalized by glyceraldehyde-3-phosphate dehydrogenase (GAPDH) score as 1.0] are shown. Results represent an average of three independent experiments. ${ }^{*} P<0.1$, ${ }^{* *} P<0.05$ (non-stimulated versus stimulated cells with $\mathrm{CHI} 3 \mathrm{~L} 1)$.

incorporated COLO 205 cells were observed (Figure 6A). To further quantify the response, the BrdU incorporation index was examined in two distinct characters of colonic epithelial cell lines. SW480 cells have an ability to produce CHI3L1 constitutively, but COLO205 cells do not have this ability. ${ }^{5}$ Purified $\mathrm{CHI} 3 \mathrm{~L} 1$ showed significantly enhanced growth-stimulating effects in a dose-dependent manner detected by BrdU incorporation in both cell lines (Figure 6B). The proliferation-stimulating effects of $\mathrm{CHI}$ 3L1 were very similar to those of IGF-1, a well-characterized growth factor and a potent inhibitor of programmed cell death (Figure 6B). Therefore, like IGF-1, $\mathrm{CHI}$ L1 has growth-stimulating effects not only for connective tissue cells but also for CECs.

\section{CHI3L1 Promotes Cellular Migratory Function of CECS}

We next investigated whether $\mathrm{CHI} 3 \mathrm{~L} 1$ facilitated $\mathrm{CEC}$ migration. To prove this, we set up an in vitro model of cellular migration using a previously established Boyden chamber system. ${ }^{25}$ As shown in Figure 7, A and B, CHI3L1-stimulated SW480 cells showed sixfold higher migration rates compared with the non-stimulated cells. To confirm that the enhanced cellular migration is mediated by $\mathrm{CHI}$ L 1 , studies to inhibit CHI3L1 activity were performed. $\mathrm{CHI}$ L 1 activity was neutralized by incubating
SW480 cells with anti-CHI3L1 polyclonal antibody or control normal rabbit IgG for 2 hours before treatment with $\mathrm{CHI}$ L1 protein. Anti-CHI3L1 antibody significantly $(P<$ $0.05)$ reduced the migration rate compared with normal rabbit IgG (Figure 7B). This result suggests that the enhanced migration effect of SW480 cells is specifically mediated by CHI3L1.

\section{Discussion}

It is well known that the risk of colon cancer for persons with IBD increases around 8 to 10 years after the initial diagnosis and that the risk is approximately five times higher than for the general population. Important risk factors include family history of colon cancer, disease duration/extent, degree of inflammation, and complication of primary sclerosing cholangitis. ${ }^{31-33}$ Essentially, all colitis-associated cancers are believed to develop from dysplastic precursor lesions. ${ }^{30}$ To detect microscopic
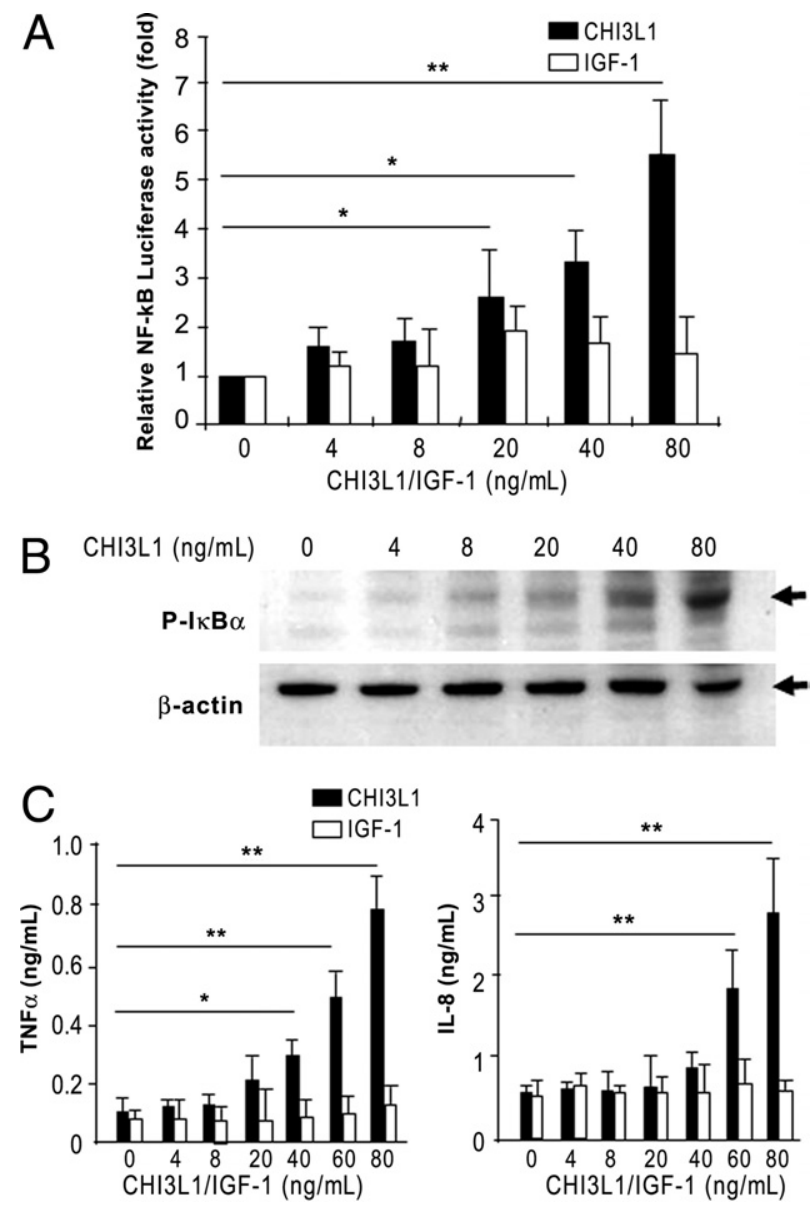

Figure 5. $\mathrm{CHI} 3 \mathrm{~L} 1$ activates $\mathrm{NF}-\kappa \mathrm{B}$ signaling pathway in a concentrationdependent manner. A: NF- $\kappa$ B activity in SW480 cells was determined 24 hours after stimulation with purified CHI3L1 or recombinant IGF-1 using $\mathrm{NF}-\boldsymbol{\kappa} \mathrm{B}$ luciferase reporter assay and normalized with Renilla. B: Protein expression of phosphorylated-IkB $\alpha$ and $\beta$-actin were analyzed by Western blot analysis as detailed in Materials and Methods. C: TNF- $\alpha$ (left) and IL-8 (right) secreted in the culture supernatant of SW 480 cells were detected by ELISA. Cells were stimulated with 0 to $80 \mathrm{ng} / \mathrm{mL}$ of purified CHI3L1 or recombinant IGF-1 for 24 hours. The data shown are the means \pm SEM from triplicate culture for each concentration. ${ }^{*} P<0.05$, ${ }^{* * *} P<0.01$ (non-stimulated versus stimulated cells with CHI3L1 or IGF). 


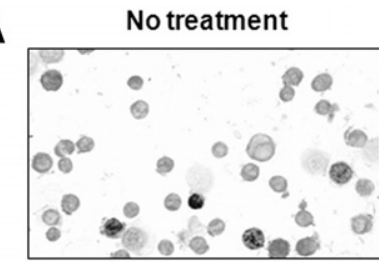

B COLO 205

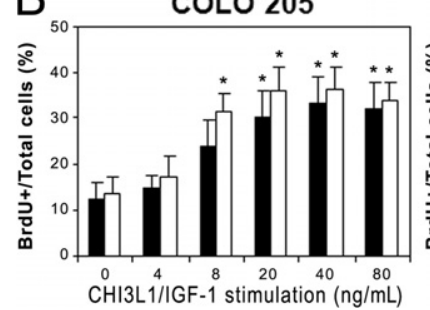

$\mathrm{CHI3L} 180 \mathrm{ng} / \mathrm{mL}$

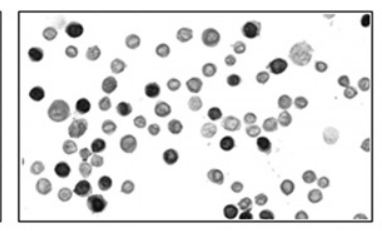

SW480

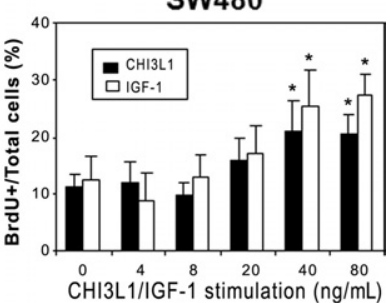

Figure 6. Purified $\mathrm{CHI} 3 \mathrm{~L} 1$ protein enhances epithelial proliferation. A: COLO 205 colonic epithelial cells were treated with (right) or without (left) purified CHI3L1 at $80 \mathrm{ng} / \mathrm{mL}$, pulse-labeled with $10 \mu \mathrm{mol} / \mathrm{L} \mathrm{BrdU}$ (Sigma) for 1 hour, and detected by anti-BrdU antibody as detailed in Materials and Methods. B: BrdU-labeled cells were determined in COLO205 (left) and SW480 (right) colonic epithelial cells stimulated with different concentration of YKL-40 (closed bars) and IGF-1 (open bars). The data shown are the means $\pm \mathrm{SD}$ from triplicate culture for each concentration. ${ }^{*} P<0.05$ (nonstimulated versus stimulated cells with CHI3L1 or IGF).

foci of dysplasia or an early stage of carcinoma, patients with IBD are advised to undergo an annual colonoscopy with multiple biopsies. However, data are limited regarding the mechanisms leading to colitis-associated cancer. In this study, we demonstrated that the expression levels of $\mathrm{CHI} 3 \mathrm{~L} 1$ are significantly increased in colonic biopsies of non-dysplastic mucosa of patients with UC harboring neoplastic lesions when compared with healthy persons or patients with UC who do not have dysplasia. Enhanced CHI3L1 expression seems to be a useful marker for predicting malignant transformation in patients with $U C$, and heterogeneous cell types, including macrophages, dendritic-like cells, fibroblasts, and CECs, actively produce CHI3L1 in dysplastic colon. In particular, the emergence of specific CHI3L1-positive cells, including Paneth cells, triangular-shaped cells, and/or neuroendocrine-like cells, in colonic epithelium in patients with chronic UC appears to be strongly associated with malignant transformation. These findings are consistent with an animal model of inflammation-associated gastric cancer, the Helicobacter felis-infected hypergastrinemic transgenic mice (FVB/N background), where CHI3L1 is one of only 31 up-regulated cDNAs compared with three different control groups. ${ }^{32}$ Our data support the hypothesis that increased CHI3L1 levels in epithelial cells are strongly associated with inflammation-associated malignant transformation in CECs. As reported by Johansen, ${ }^{9}$ epithelial cells that express CHI3L1 may have a different phenotype compared with epithelial cells without CHI3L1 expression, and the protein may reflect differences in the biology of epithelial cells and cancer cells.

Human and mouse CHISL1 have been identified as proteins expressed during conditions of tissue remodeling, ${ }^{1,2}$ atherogenesis, ${ }^{33}$ and processes that are associated with changes in cell adhesion and migration. ${ }^{34-36}$ An elevated serum CHI3L1 level also was an indepen-

dent prognostic parameter of metastatic cancer, ${ }^{35}$ suggesting that $\mathrm{CHI} 3 \mathrm{~L} 1$ may be a growth factor of cancer cells and/or may prevent them from apoptosis. ${ }^{9}$ However, it is unclear whether the increased $\mathrm{CHI} 3 \mathrm{~L} 1$ expression is observed only in the lesions undergoing malignant transformation or whether the expression is already up-regulated in nonneoplastic regions of the colon that carry both UC and dysplasia/adenocarcinoma. It also is unclear whether secreted $\mathrm{CHI} 3 \mathrm{~L} 1$ directly regulates the cell proliferation and migration of CECs. To address these important questions, we designed the current study and found that $\mathrm{CHI} 3 \mathrm{~L} 1$ expression was up-regulated in distinct cell types of crypt epithelial cells in both dysplastic and non-dysplastic areas of the colon with UC that had developed dysplasia/adenocarcinoma. Furthermore, the extent of CHI3L1 expression in tumor cells was associated with invasiveness and metastasis. We also found that soluble $\mathrm{CHI} 3 \mathrm{~L} 1$ protein, which was purified from culture supernatant of osteoblastic MG-63 cells, enhances $I_{\kappa} \mathrm{B} \alpha$ phosphorylation, NF- $\kappa \mathrm{B}$ signaling activation, and pro-inflammatory cytokine production after 3 hours of stimulation in vitro. We also showed that CECs produce $\mathrm{IL}-8$ in response to soluble $\mathrm{CHI} 3 \mathrm{~L} 1$. We postulate that IL-8 induction is likely controlled by an activation of signaling through the NF- $\kappa$ B cascade because only a few selected genes in the NF- $\kappa \mathrm{B}$ pathway were activated by $\mathrm{CHI} 3 \mathrm{~L} 1$ at this time point by $\mathrm{NF}-\kappa \mathrm{B}$ signaling pathway microarray. However, the involvement of other pathways, including mitogen-activated protein kinase p42/p44 and phospho-
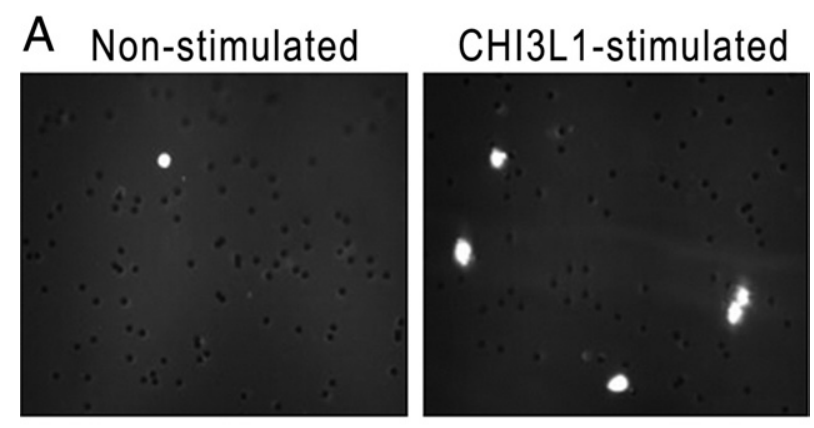

B

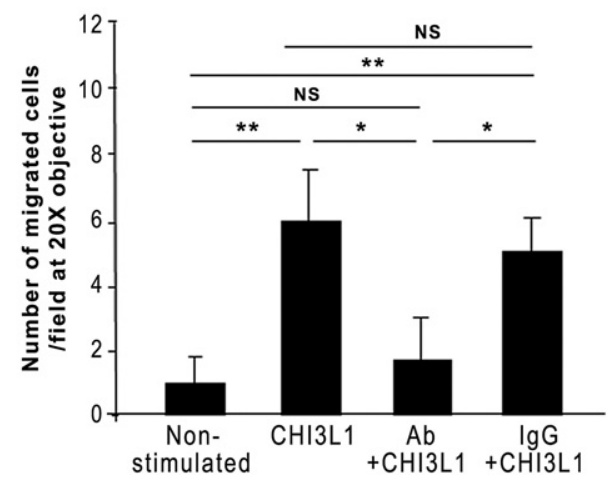

Figure 7. CHI3L1 enhances a cellular migration of CECs. A: SW480 cells in the presence of $50 \mathrm{ng} / \mathrm{mL} \mathrm{CHI3L1} \mathrm{protein} \mathrm{(right)} \mathrm{or} \mathrm{PBS} \mathrm{(left)} \mathrm{were} \mathrm{seeded}$ on a transwell filter insert in a modified Boyden chamber. The migrating cells were fixed on the filter after 24 hours, stained with DAPI, and counted under the microscope. Representative image of migrated cells were shown. B: The number of migrated cells was counted per field of $20 \times$, objective, and data represent a mean value with SEM of three independent experiments in each group. ${ }^{*} P<0.05,{ }^{* *} P<0.01$. NS, not significant. 
inositide 3-kinase/protein kinase $\mathrm{B}$, has not been excluded. In general, activated NF- $\kappa \mathrm{B}$ is found in inflamed colon in patients with IBD, ${ }^{36}$ and TNF- $\alpha$ induces strong $\mathrm{NF}-\kappa \mathrm{B}$ activity and promotes tumor development in models of experimental colitis. ${ }^{37} \mathrm{NF}-\kappa \mathrm{B}$ efficiently stimulates the proliferation of tumor cells and enhances their survival by up-regulating the expression of anti-apoptotic genes. ${ }^{38}$ In addition, constitutive activation of NF- $\kappa$ B has been demonstrated recently in colitis-associated cancer, ${ }^{39}$ assessed by a constitutive activation in RelA, RelB, and NF- $\kappa$ B1 in colon cancer. ${ }^{40}$ Therefore CHI3L1 may control intestinal inflammation and presumably enhance the subsequent dysplastic changes in CECs by activating the NF- $\kappa \mathrm{B}$ signaling cascade that induces pro-inflammatory cytokines, including TNF- $\alpha$ and IL-8. Based on these observations, we speculate that $\mathrm{CHI} 3 \mathrm{~L} 1$-mediated $\mathrm{NF}-\kappa \mathrm{B}$ activation in CECs may play a critical role to initiate and/or accelerate the dysplastic change in chronic IBD.

Increased serum CHI3L1 levels often are found in patients with liver metastases of colorectal cancers. ${ }^{26,27}$ The development of liver metastases involves several steps, including invasion of tumor cells from the primary site into vessels, adhesion to the endothelium, extravasation in the hepatic microvasculature, and multiplication and formation of tumor deposits in the liver parenchyma. ${ }^{9}$ In this study, CHI3L1 was highly expressed in neuroendocrine cells in patients with UC who had primary colonic adenocarcinoma and was associated with and may have contributed to the development of liver metastasis (Figure $3, \mathrm{~J}-\mathrm{L}$ ). In addition, CHI3L1 efficiently stimulates SW480 cellular proliferation and migration as shown in Figures 6 and 7. Shao et $\mathrm{al}^{41}$ also demonstrated that ectopic CHI3L1 expression in HCT-116 colon cancer cells led to extensive angiogenesis and tumor progression compared with empty vector transduced control cancer cells in a xenograft mouse model. In addition, CHI3L1 has an anti-apoptotic effect by enhancing the activation of mitogen-activated protein kinase and phosphoinositide 3-kinase signaling cascades. ${ }^{11,42}$ The phosphoinositide 3-kinase pathway-in particular, the phosphorylation of protein kinase B-is strongly associated with cell survival, ${ }^{43}$ and we have previously reported that soluble CHI3L1 efficiently stimulates the nuclear translocation of $\beta$-catenin in SW480 cells. ${ }^{44}$ Therefore, not only during the tumor metastatic phase but also during the transitional phase from chronic colitis to dysplasia, CHI3L1 may effectively promote tumor development by enhancing cell proliferation, migration, angiogenesis, and cell survival in selected types of CECs (eg, triangular-shaped cells and Paneth cells) and neuroendocrine cells in colonic crypt cells.

Our current study strongly suggests that $\mathrm{CHI} 3 \mathrm{~L} 1$ plays a major role in inflammation-associated neoplastic changes in CECs. Our findings may be useful for future development of therapeutic strategies to prevent persistent and chronic epithelial cell hyperproliferation and activation during inflammatory conditions. Additional studies of CHIBL1 in animal models of colitis-associated neoplasia might help us further understand its underlying biological mechanisms.
Increased CHI3L1 expression is associated with chronic colitis-induced neoplastic changes in CECs. The mechanism by which CHI3L1 contributes to neoplastic formation is not known. In this study we have showed that $\mathrm{CHI}$ L 1 efficiently activates NF- $\kappa \mathrm{B}$ signaling pathway and subsequently enhances the secretion of pro-inflammatory cytokines such as IL-8 and TNF- $\alpha$. In addition, CHI3L1 actively promotes cellular proliferation and migration in CECs.

\section{Acknowledgments}

We thank Ramnik J. Xavier, Vijay Yajnik, Daniel Chung, Mayumi Kawada, and Elke Cario for their helpful discussion and advice, Terry Danford Lott for his excellent secretarial assistance in preparing this manuscript, Ahmadali Mardoniya Moghimi and Satoko Toei-Shimizu for their technical assistance, Drs. Atsuko Arihiro, Yuriko Hachiya, and Meiko Onitsuka for performing $\mathrm{IHC}$ analysis, and $\mathrm{Dr}$. Maria S. Pino for her professional assistance with the Boyden chamber assay.

\section{References}

1. Hakala BE, White C, Recklies AD: Human cartilage gp-39, a major secretory product of articular chondrocytes and synovial cells, is a mammalian member of a chitinase protein family. J Biol Chem 1993, 268:25803-25810

2. Hu B, Trinh K, Figueira WF, Price PA: Isolation and sequence of a novel human chondrocyte protein related to mammalian members of the chitinase protein family. J Biol Chem 1996, 271:19415-19420

3. Jin HM, Copeland NG, Gilbert DJ, Jenkins NA, Kirkpatrick RB, Rosenberg M: Genetic characterization of the murine $\mathrm{Ym} 1$ gene and identification of a cluster of highly homologous genes. Genomics 1998 , 54:316-322

4. Kzhyshkowska J, Mamidi S, Gratchev A, Kremmer E, Schmuttermaier C, Krusell L, Haus G, Utikal J, Schledzewski K, Scholtze J, Goerdt S: Novel stabilin-1 interacting chitinase-like protein (SI-CLP) is up-regulated in alternatively activated macrophages and secreted via lysosomal pathway. Blood 2006, 107:3221-3228

5. Mizoguchi E: Chitinase 3-like-1 exacerbates intestinal inflammation by enhancing bacterial adhesion and invasion in colonic epithelial cells. Gastroenterol 2006, 130:398-411

6. Krause SW, Rehli M, Kreutz M, Schwarzfischer L, Paulauskis JD, Andreesen R: Differential screening identifies genetic markers of monocyte to macrophage maturation. J Leukoc Biol 1996, 60:540-545

7. Renkema GH, Boot RG, Au FL, Donker-Koopman WE, Strijland A, Muijsers AO, Hrebicek M, Aerts JM: Chitotriosidase, a chitinase, and the 39-kDa human cartilage glycoprotein, a chitin-binding lectin, are homologues of family 18 glycosyl hydrolases secreted by human macrophages. Eur J Biochem 1998, 251:504-509

8. Johansen JS, Olee T, Price PA, Hashimoto S, Ochs RL, Lotz M Regulation of YKL40 production by human articular chondrocytes. Arthritis Rheum 2001, 44:826-837

9. Johansen JS: Studies on serum YKL-40 as a biomarker in diseases with inflammation, tissue remodeling, fibroses and cancer. Dan Med Bull 2006, 53:172-209

10. De Ceuninck F, Gaufillier S, Bonnaud A, Sabatini M, Lesur C, Pastoureau P: YKL-40 (cartilage gp-39) induces proliferative events in cultured chondrocytes and synoviocytes and increases glycosaminoglycan synthesis in chondrocytes. Biochem Biophys Res Commun 2001, 285:926-931

11. Recklies $A D$, White $C$, Ling $H$ : The chitinase 3 -like protein human cartilage glycoprotein 39 (HC-gp39) stimulates proliferation of human connective-tissue cells and activates both extracellular signal-regulated kinase- and protein kinase B-mediated signaling pathways. Biochem J 2002, 365:119-126 
12. Kirkpatrick RB, Emery JG, Conno JR, Dodds R, Lysko PG, Rosenberg $M$ : Induction and expression of human cartilage glycoprotein 39 in rheumatoid inflammatory and peripheral blood monocyte-derived macrophages. Exp Cell Res 1997, 237:46-54

13. Johansen JS, Stoltenberg M, Hansen M, Florescu A, Hørslev-Petersen K, Lorenzen I, Price PA: Serum YKL-40 concentrations in patients with rheumatoid arthritis: relation to disease activity. Rheumatology 1999, 38:618-626

14. Chupp GL, Lee CG, Jarjour N, Shim YM, Holm CT, He S, Dziura JD, Reed J, Coyle AJ, Kiener P, Cullen M, Grandsaigne M, Dombret MC, Aubier M, Pretolani M, Elias JA: A chitinase-like protein in the lung and circulation of patients with severe asthma. N Eng J Med 2007, 357: 2016-2027

15. Vind I, Johansen JS, Price PA, Munkholm P: Serum YKL-40, a potential new marker of disease activity in patients with inflammatory bowel disease. Scand J Gastroenterol 2003, 38:599-605

16. Punzi L, Podwiadek M, D'luca R, Zaninotto M, Bernardi D, Plebani M Sturniolo GC: Serum human cartilage glycoprotein 39 as a marker of arthritis associated with inflammatory bowel disease. Ann Rheum Dis 2003, 62:1224-1226

17. Koutroubakis IE, Petinaki E, Dimoulios P, Vardas E, Roussomoustakaki M, Maniatis AN, Kouroumalis EA: Increased serum levels of YKL-40 in patients with inflammatory bowel disease. Int J Colorectal Dis 2003, 18:254-259

18. Eaden JA, Abrahams KR, Mayberry JF: The risk of colorectal cancer in ulcerative colitis: a meta-analysis. Gut 2001, 48:526-535

19. Seruga B, Zhang H, Bernstein LJ, Tannock IF: Cytokines and their relationship to the symptoms and outcome of cancer. Nat Rev Cancer 2008, 8:887-899

20. Danese S, Mantovani A: Inflammatory bowel disease and intestinal cancer: a paradigm of the Yin-Yang interplay between inflammation and cancer. Oncogene 2010, 28:3313-3323

21. Johansen JS, Jensen BV, Roslind A, Nielsen D, Price PA: Serum YKL-40, a new prognostic biomarker in cancer patients? Cancer Epidemiol Biomarkers Prev 2006, 15:194-202

22. Harvey S, Weisman M, O'Dell J, Scott T, Krusemeier M, Visor J Swindlehurst C: Chondrex: new marker of joint disease. Clin Chem 1998, 44:509-516

23. Mombaerts $P$, Mizoguchi E, Grusby MJ, Glimcher LH, Bhan AK, Tonegawa S: Spontaneous development of inflammatory bowel disease in T cell receptor mutant mice. Cell 1993, 75:275-282

24. Mizoguchi E, Mizoguchi A, Bhan AK: Role of cytokines in the early stages of chronic colitis in TCR $\alpha$-mutant mice. Lab Invest 1997, 76:385-397

25. Dhar G, Banerjee S, Dhar K, Tawfik O, Mayo MS, Vanveldhuizen PJ, Banerjee SK: Gain of oncogenic function of p53 mutants induces invasive phenotypes in human breast cancer cells by silencing CCN5/WISP-2. Cancer Res 2008, 68:4580-4587

26. Cintin C, Johansen JS, Christensen IJ, Price PA, Sorensen S, Nielsen HJ: Serum YKL-40 and colorectal cancer. Br J Cancer 1999, 79: 1494-1499

27. Cintin C, Johansen JS, Christensen IJ, Price PA, Sorensen S, Nielsen $\mathrm{HJ}$ : High serum YKL-40 level after surgery for colorectal carcinoma is related to short survival. Cancer 2002, 95:267-274

28. Itzkowitz SH, Yao X: Inflammation and cancer IV. Colorectal cancer in inflammatory bowel disease: the role of inflammation. Am J Gastrointest Liver Physiol 2004, 287:G7-G17
29. Kornfeld D, Ekbom A, Ihre T: Is there an excess risk for colorectal cancer in patients with ulcerative colitis and concomitant primary sclerosing cholangitis? A population based study. Gut 1997, 41: 522-525

30. Vera A, Gunson BK, Ussatoff V, Nightingale P, Candinas D, Radley S, Mayer AD, Buckels JA, McMaster P, Neuberger J, Mirza DF: Colorectal cancer in patients with inflammatory bowel disease after liver transplantation for primary sclerosing cholangitis. Transplantation 2003, 75:1983-1988

31. Lakatos L, Mester G, Erdelyi Z, David G, Pandur T, Balogh M, Fisher S, Vargha P, Lakatos PL: Risk factor for ulcerative colitis-associated colorectal cancer in a Hungarian cohort of patients with ulcerative colitis: results of a population-based stuffy. Inflamm Bowel Dis 2006, 12:205-211

32. Takaishi S, Wang TC, Gene expression profiling in a mouse model of Helicobacter-induced gastric cancer. Cancer Sci 2007, 98:284-293

33. Boot RG, Van Achterberg TAE, van Aken BE, Renkema GH, Jacobs MJHM, Aerts JMFG, de Vries CJ: Strong induction of members of the chitinase family of proteins in atherosclerosis: chitotriosidase and human cartilage gp-39 expressed in lesion macrophages. Arterioscler Thromb Vasc Biol 1999, 19:687-694

34. Nishikawa KC, Millis AJT: gp38k (CHI3L1) is a novel adhesion and migration factor for vascular cells. Exp Cell Res 2003, 287:79-87

35. Brasso K, K., Christensen IJ, Johansen JS, Teisner B, Garnero P, Price PA, Iversen P. 2006. Prognostic value of PINP, bone alkaline phosphatase, CTX-1, and YKL-in patients with metastatic prostate carcinoma. Prostate 2006, 66:503-513

36. Roger G, Brand K, Vogl D, Page S, Hofmeister R, Andus T, Knuechel R, Baeuerle PA, Scholmerich J, Gross V: Nuclear factor kB is activated in macrophages and epithelial cells of inflamed intestinal mucosa. Gastroenterology 1998, 115:357-369

37. Popivanova BK, Kitamura K, Wu Y, Kagaya T, Kaneko S, Oshima M, Fujii C, Mukaido N: Blocking TNF-alpha in mice reduces colorecta carcinogenesis associated with chronic colitis. J Clin Invest 2008, 118:560-570

38. Kraus S, Arber N: Inflammation and colorectal cancer. Curr Opin Pharmacol 2009, 9:405-410

39. Sakamoto $K$, Maeda S, Hikiba $Y$, Nakagawa $H$, Hayakawa $Y$, Shibata W, Yanai A, Ogura K, Omata M: Constitutive NF- $\kappa$ B activation in colorectal carcinoma plays a key role in angiogenesis, promoting tumor growth. Clin Cancer Res 2009, 15:2248-2258

40. Dolce X, Llobet D, Pallares J, Matis-Guiu X: NF- $\kappa$ B in development and progression of human cancer. Virhows Arch 2005, 446:475-482

41. Shao R, Hamel K, Petersen L, Cao QJ, Arenas RB, Bigelow C, Bentley B, Yan W: YKL-40, a secreted glycoprotein, promotes tumor angiogenesis. Oncogene 2009, 28:4456-4468

42. Lee CG, Silva CD, Dela Cruz CS, Ahangari F, Ma B, Kang MJ, $\mathrm{He} \mathrm{CH}$, Takyar S, Elias JA: Role of chitin and chitinase/chitin-like proteins in inflammation, tissue remodeling, and injury. Annu Rev Physiol 2011, 73:479-501

43. Bakkenist CJ, Kastan MB: Initiating cellular stress responses. Cell 2004, 118:9-17

44. Eurich K, Segawa M, Toe-Shimizu S, Mizoguchi E: Potential role of chitinase 3-like-1 in inflammation-associated carcinogenic changes of epithelial cells. World J Gastroenterol 2009, 15:5249-5259 